\title{
Drivers and Modalities of Collaborative Innovation among Nairobi's Mobile Tech Start-Ups
}

\section{Victor Nzomo}

PhD Candidate, Faculty of Law, University of Cape Town; and Research Alumnus, Centre for Intellectual Property and Information Technology Law (CIPIT), Strathmore University, Nairobi, and Open African Innovation Research (Open AIR) network

(iD https://orcid.org/0000-0001-5336-7138

\section{Jacquelene Mwangi}

SJD Candidate, Harvard Law School, Cambridge, MA; and Research Alumna, Centre for Intellectual Property and Information Technology Law (CIPIT), Strathmore University, Nairobi, and Open African Innovation Research (Open AIR) network

(iD) https://orcid.org/0000-0002-8197-5293

\section{Louisa Matu-Mureithi}

Research Alumna, Centre for Intellectual Property and Information Technology Law (CIPIT), Strathmore University, Nairobi, and Open African Innovation Research (Open AIR) network

(iD https://orcid.org/0000-0002-4967-5231

\section{Caroline Wanjiru Muchiri}

Research Fellow, Centre for Intellectual Property and Information Technology Law (CIPIT), Strathmore University, Nairobi; and Researcher, Open African Innovation Research (Open AIR) network

(iD https://orcid.org/0000-0002-7662-3920

\section{Isaac Rutenberg}

Senior Lecturer and Director, Centre for Intellectual Property and Information Technology Law (CIPIT), Strathmore University, Nairobi; and Steering Committee Member, Open African Innovation Research (Open AIR) network

(iD https://orcid.org/0000-0003-0969-4523

\begin{abstract}
This article sets out findings from research into the collaborative modalities present in the innovation practices of mobile tech start-ups in the Kenyan capital, Nairobi. Drawing on findings from qualitative data collection from respondents at 25 startups in the Nairobi mobile tech ecosystem, the study explores the start-ups' participation in tech hubs, their internal collaborative activities, their external collaborations, their approaches to managing the knowledge and innovations they generate, and their approaches to the scaling of their enterprises. The study finds that three key drivers of the start-ups' collaborative innovation practices are openness, networking, and informality.
\end{abstract}




\section{Keywords}

mobile tech start-ups, tech hubs, innovation, collaboration, human resource development, knowledge governance, scaling, partnerships, networking, openness, informality, Nairobi, Kenya

\section{Acknowledgements}

The research for this article was conducted by the Centre for Intellectual Property and Information Technology Law (CIPIT) at Strathmore University in Nairobi, under the auspices of the Open African Innovation Research (Open AIR) network. Open AIR is a partnership between Strathmore University, the University of Cape Town, the University of Johannesburg, the Nigerian Institute of Advanced Legal Studies, The American University in Cairo, and the University of Ottawa. The authors acknowledge the support provided for this research by Open AIR, the Social Sciences and Humanities Research Council (SSHRC) of Canada, and the International Development Research Centre (IDRC). The views expressed in this work are those of the authors and do not necessarily represent those of the research funders. The authors wish to extend special thanks to Miriam Wanjiku Karanja for extensive reviewing and editing. This article draws on elements of a working paper (Nzomo et al., 2020).

DOI: $\underline{\text { https://doi.org/10.23962/10539/30359 }}$

\section{Recommended citation}

Nzomo, V., Mwangi,J., Matu-Mureithi, L., Muchiri, C. W., \& Rutenberg, I. (2020). Drivers and modalities of collaborative innovation among Nairobi's mobile tech startups. The African Journal of Information and Communication (AJIC), 26, 1-24.

https://doi.org/10.23962/10539/30359

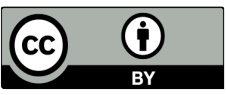

This article is licensed under a Creative Commons Attribution 4.0 International (CC BY 4.0) licence: https://creativecommons.org/licenses/by/4.0

\section{Introduction}

Kenya has been hailed as Africa's “epicentre of innovation” (Moime, 2016), with its digital innovation activities in and around the capital, Nairobi, coming to be known as the "Silicon Savannah". Kenya's tech innovation start-up sector is, to a great extent, focused on innovations for use on mobile handsets. Since the launch of the M-PESA mobile money application (app) in 2007 by Kenyan mobile operator Safaricom, the country has seen the growth of a large and vibrant mobile app development ecosystem. Many start-ups leverage the M-PESA platform to create solutions in online financial services (fintech) and related sectors (Mwangi, 2017). At the same time, 
Kenya's mobile tech start-ups are also engaged in developing mobile tech solutions in a wide range of other key sectors, including agriculture (see Karuga, 2013) and healthcare (see Lawrence-Brown \& Nieminen, 2016).

Among the many factors seen as responsible for the rapid development and uptake of mobile technology innovation in Kenya, and across the African continent, is the proliferation of technology hubs (hereafter "tech hubs") (see Adesida et al., 2016; De Beer et al., 2017; Kaigwa, 2010; The Economist, 2012). These spaces provide business support in the form of mentorship, office facilities, networking opportunities, and seed funding. Through a tech hub, a mobile tech start-up is potentially able to receive support for its efforts to move from the idea stage to the minimum viable prototype stage, and then to take a product or service to market. In Kenya, perhaps the bestknown tech hub is iHub, which has been singled out by numerous commentators as making a core contribution to the Kenyan mobile start-up scene (see, for example, The Economist, 2012).

Elements seen as central to innovation practices in many African settings are openness and collaboration (see, for example, De Beer et al., 2014; Pembroke, 2015; Smith \& Reilly, 2013; Smith \& Seward, 2020). Open and collaborative approaches to innovation, supported by flexible, non-exclusive approaches to knowledge governance, have been found to be central to the success, and efforts to scale, exhibited by many knowledge-based enterprises on the continent (see De Beer et al., 2014; Open AIR, 2020). With respect to start-ups, as Pembroke (2015) points out, there are so many challenges that none can succeed by going it alone, and, through collaboration, entrepreneurs can counter some of the inherent challenges of entrepreneurship (Pembroke, 2015).

The goal of this study was to explore the approaches to, and dimensions of, collaboration as being practised by Nairobi's mobile tech start-ups. We were also interested in the start-ups' approaches to knowledge governance and to scaling, as dimensions linked to their approaches to collaboration. Accordingly, we conducted a qualitative survey of the experiences and perceptions of representatives of 25 mobile tech start-ups engaged in the following sectors: fintech, bitcoin, community development, healthcare, hospitality, security, geospatial services, marketing, advertising, transportation, education, agriculture, real estate, software development, automation, IoT (internet of things), and outsourcing.

As is presented in this article, the data produced compelling findings on the drivers and modalities of the start-up innovators' collaborations, knowledge governance, and scaling. We were also able to identify, in the data, three cross-cutting dimensions that seem to be core animators of the start-ups' innovation practices: openness, networking, and informality. 


\section{Context}

\section{Kenyan start-ups}

Start-ups in Kenya are, for the most part, micro and small enterprises (MSEs). In terms of the country's Micro and Small Enterprises Act of 2012 (hereafter "MSE Act"), micro enterprises have an annual turnover of less than KES500,000 (approximately USD4,600 in late 2020) and fewer than 10 employees, with small enterprises having an annual turnover of between KES500,000 and KES5 million (i.e., between USD4,600 and USD46,000) and between 10 and 50 employees (Republic of Kenya, 2012). In qualitative terms, we agree with Robehmed's (2013) conception of startups as entities "working to solve a problem where the solution is not obvious and success is not guaranteed".

Kenya's Vision 2030 development strategy recognises the need to strengthen startups and MSEs (GoK, 2007). The MSE Act, in line with Vision 2030, positions start-ups, particularly tech start-ups, as drivers of innovation. Start-up culture is characterised by "[a] workplace environment that values creative problem solving, open communication and a flat hierarchy" (Rouse, 2014). Such an environment aims, among other things, to provide an opportunity for the people working at the startup to grow organically with it, even if employees ultimately decide to exit the company and, in many cases, launch their own start-ups. Start-up culture also typically involves flexible approaches to knowledge governance-i.e., innovative modes of knowledge-sharing and knowledge appropriation, often with an emphasis on informal modes. It has been found that the use of formalised intellectual property (IP) tools to appropriate knowledge among Kenya's knowledge-based businesses is minimal (Masinde, 2016; Rutenberg, 2013; WIPO, 2016).

In the period 2018 to 2019, funding of Kenyan tech start-ups was put at USD122 million (Disrupt Africa, 2019). Among the elements central to the growth of mobile tech innovation in Kenya are the aforementioned M-PESA mobile money platform and, in turn, the country's mobile money and fintech market (Mengistu \& Imende, 2013; Pasquier, 2014; The Economist, 2012). Since the launch of M-PESA in 2007, and the subsequent opening of its application programming interface (API) to developers in 2015 (Mutegi, 2015), the Kenyan fintech sector has been transformed by numerous start-ups developing new M-PESA-linked products and services (see Adongo, 2015). In March 2020, Kenya, with a population of approximately 47.5 million, had 55.2 million active mobile subscriptions (a penetration of $116.1 \%$ of the population, with many users having more than one mobile SIM card); 29.1 million active mobile money subscriptions (61\% penetration); and 202,102 active mobile money agents (CAK, 2020).

The emergence of Safaricom and its associated services, including M-PESA, was made possible by the deregulation of Kenya's telecommunications industry, starting in 1999. Several socio-economic factors have also contributed to the explosive uptake 
of M-PESA and other mobile money transfer systems, including: the low number of Kenyans with bank accounts (and, in turn, credit cards); the high number of urban Kenyans who support relatives in rural areas; and security problems posed by transferring funds by hand or through intermediaries, e.g., via bus transport (Mengistu \& Imende, 2013). Government support for Kenya's connections to international undersea fibre optic data cable projects, through strategic partnerships with the private sector, has also contributed by making broadband internet widely available and affordable (Mengistu \& Imende, 2013).

\section{Tech hubs and collaborative innovation}

In mid-2019, according to one calculation, there were 681 active tech hubs across the continent (Giuliani \& Adaji, 2019). Africa's tech hubs can be understood in terms of three prevailing hub "archetypes" (see De Beer et al., 2017):

- cluster hub: A small geographical region, e.g., a neighbourhood or urban corridor, containing a number of individual hub entities that frequently interact. Nairobi's Ngong Road is an example of a cluster hub, as it is home to iHub, Nailab, m:Lab East Africa, and Nairobi Garage.

- company hub: An individual hub entity serving a particular community of innovators, "interacting with the outside world in a manner similar to a company" (De Beer et al., 2017, p. 250) and operating either as part of a cluster hub or in a more stand-alone fashion.

- country bub: "a more macro view of a hub, where an entire country or region advertises itself as a progressive hub, and government policies guide the actions of the country or region" (De Beer et al., 2017, p. 250).

African tech hubs' culture of openness has generated support from many development partners, who believe that open collaboration holds the key to the success of start-ups on the continent, and who further believe that tech hubs can enable sustainable tech entrepreneurship. Tech hubs have been credited with fostering collaboration-enabling environments where start-ups can meet new people, find resources and investors, and test their business models (Pembroke, 2015). Since its establishment, Nairobi's iHub has sought to build an innovation community committed to sharing and collaboration, and these objectives were also central to the establishment of m:Lab in the same building as iHub (Gathege \& Moraa, 2013). iHub seeks to create an environment for open innovation and collaboration between developers, academia, industry, venture capitalists, and investors (Gathege \& Moraa, 2013). Its key vehicles for collaborative innovation are hackathons and competitions, during which ideas are openly shared. M-Farm and Rupu are among the start-ups that materialised after such iHub events. It has been argued that, as part of their internal collaboration processes, start-ups seeking to develop their human resources need to leverage the skills of current employees by ensuring that they serve as trainers (Bahrami, 2016). 
For tech-based start-ups, a key form of collaboration is the interaction between individuals inside the organisation, where everyone works together to achieve a clear and shared aim in a specific context (Lopez Hernandez et al., 2018). The impact of collaboration on innovation is to some extent dependent on the nature of the partners involved in the process (Faems et al., 2005). In instances where collaboration is between a start-up and an established company, the value derived by each firm will be dependent on each actor's strengths (Steiber \& Sverker, 2020). Organisations can harness collaboration in various ways, including internally through configuring their infrastructures in a manner that enables the sharing of ideas, and externally through their choices of location. Jiménez and Zheng (2018) argue that tech hubs' collaborative processes can contribute to human-centred development dimensions that are broader than employment and product development benefits.

Organisations can adopt closed or open models in their collaborative efforts. Closed innovation models are characterised by enterprises' efforts to, among other things, isolate their innovations and to keep them secret (De Beer, 2017, p. 17). Open collaboration models perform robustly not only in software innovation domains but also in many other types of ventures (Levine \& Prietula, 2014). There is now a growing adoption of open collaborative models of innovation that can, for example, break down barriers to knowledge flows between enterprises (De Beer, 2017, p. 17). In Kenya, as mentioned above, the leading mobile telephone service provider, Safaricom, opened the application programming interface (API) for its M-PESA mobile money services in 2015. This opening was aimed at nurturing open innovation in Kenya (Safaricom, n.d.).

\section{Research design}

\section{Methodology}

The study used desk research to generate secondary data, and a survey questionnaire to produce primary data. In the desk research, basic information was gathered on all the start-ups that could be traced to Nairobi tech hubs, with contact information stored for the purposes of sourcing respondents for the administration of a semi-structured survey questionnaire, as outlined below. The desk research also yielded important background information on the start-up ecosystem in Kenya, including relevant reports, studies, and news articles. Based on the findings from the desk research, 25 start-ups in Nairobi were selected. Key resource persons at the start-ups were identified and contacted, and their inputs received through a semi-structured survey questionnaire administered via one of four means: an in-person interview, a phone interview, an online video interview, or respondent completion of the questionnaire in writing online. All interviews were audio-recorded and transcribed. 


\section{Questionnaire}

The questionnaire (see Appendix) focused its questioning on the following elements of the 25 start-ups' mobile tech innovation practices:

- establishment, registration, duration of operations, human resources;

- $\quad$ sector(s), main products, types of problems addressed by innovations;

- organisation of workspaces, collaborations within the start-up, generation of business ideas;

- collaborations with external partners and stakeholders;

- sharing and protection of business knowledge and innovations; and

- approaches to the scaling of their enterprises.

\section{Respondents}

Table 1 below shows the sectors in which the 25 survey respondents' start-ups operated, the date on which the surveys were completed, and the survey mode used for each respondent.

Table 1: Respondents' sectors, survey dates, and survey modes

\begin{tabular}{|c|c|c|c|}
\hline $\begin{array}{c}\text { Respondent } \\
\text { number }\end{array}$ & Start-up's sector(s) & Survey date & Survey mode \\
\hline 1 & community development & 9 March 2017 & phone interview \\
\hline $2^{1}$ & bitcoin, fintech & 4 April 2017 & online video interview \\
\hline 3 & software development & 20 February 2017 & in-person interview \\
\hline 4 & software development & 22 February 2017 & in-person interview \\
\hline 5 & health & 3 March 2017 & in-person interview \\
\hline 6 & digital marketing & 31 March 2017 & in-person interview \\
\hline 7 & healthcare & 8 June 2017 & phone interview \\
\hline 8 & outsourcing solutions & 3 March 2017 & in-person interview \\
\hline 9 & software development & 26 May 2017 & phone interview \\
\hline 10 & restaurants, leisure & 17 April 2017 & online questionnaire \\
\hline 11 & IT solutions, security & 2 May 2017 & online questionnaire \\
\hline 12 & $\begin{array}{c}\text { IT solutions, geospatial } \\
\text { services }\end{array}$ & 9 May 2017 & online questionnaire \\
\hline 13 & IT solutions, advertising & 15 May 2017 & online questionnaire \\
\hline 14 & $\begin{array}{c}\text { IT solutions, machine } \\
\text { automation }\end{array}$ & 18 May 2017 & online questionnaire \\
\hline 15 & IoT (internet of things) & 23 May 2017 & online questionnaire \\
\hline 16 & healthcare & 24 May 2017 & online questionnaire \\
\hline 17 & $\begin{array}{l}\text { transport and route map- } \\
\text { ping }\end{array}$ & 26 May 2017 & online questionnaire \\
\hline
\end{tabular}

1 This second response to the survey was provided cooperatively by two individuals from a single startup, with each responding to the questions relevant to their area of expertise. 


\begin{tabular}{|c|c|c|c|}
\hline 18 & IoT (internet of things) & 29 May 2017 & online questionnaire \\
\hline 19 & education & 29 May 2017 & online questionnaire \\
\hline 20 & agriculture & 30 May 2017 & online questionnaire \\
\hline 21 & real estate & 6 June 2017 & online questionnaire \\
\hline 22 & fintech & 9 June 2017 & online questionnaire \\
\hline 23 & healthcare & 2 August 2017 & in-person interview \\
\hline 24 & healthcare & 2 August 2017 & in-person interview \\
\hline 25 & fintech & 3 August 2017 & in-person interview \\
\hline
\end{tabular}

Table 2 shows the gender breakdown of the 25 respondents, and their roles in their respective start-ups.

Table 2: Respondents' gender, role/position

\begin{tabular}{|c|c|c|}
\hline Characteristics & $\begin{array}{c}\text { No. of respon- } \\
\text { dents }\end{array}$ & \% of respondents \\
\hline Respondent's gender & \multicolumn{2}{|c|}{} \\
\hline Male & 19 & $76 \%$ \\
\hline Female & 5 & $20 \%$ \\
\hline Did not say & 1 & $4 \%$ \\
\hline \multicolumn{2}{|c|}{} \\
\hline Respondent's role/position in start- \\
up & 13 & $52 \%$ \\
\hline Founder/CEO & 7 & $28 \%$ \\
\hline Technical staff member & 2 & $8 \%$ \\
\hline Director & 3 & $12 \%$ \\
\hline Other & \multicolumn{2}{|c|}{} \\
\hline
\end{tabular}


Table 3 shows the core characteristics of the 25 start-ups that the respondents represented.

Table 3: Core characteristics of the 25 start-ups

\begin{tabular}{|c|c|c|}
\hline Characteristics & $\begin{array}{c}\text { No. of } \\
\text { start-ups }\end{array}$ & $\%$ of start-ups \\
\hline \multicolumn{3}{|l|}{ Number of employees in start-up } \\
\hline $1-3$ & 3 & $12 \%$ \\
\hline $4-6$ & 8 & $32 \%$ \\
\hline $7-9$ & 5 & $20 \%$ \\
\hline $10-12$ & 2 & $8 \%$ \\
\hline $13-15$ & 3 & $12 \%$ \\
\hline 16 and above & 4 & $16 \%$ \\
\hline \multicolumn{3}{|l|}{ Legal status of start-up } \\
\hline Sole proprietorship business & 3 & $12 \%$ \\
\hline Not-for-profit entity & 1 & $4 \%$ \\
\hline Limited liability partnership & 2 & $8 \%$ \\
\hline Limited liability company & 19 & $76 \%$ \\
\hline \multicolumn{3}{|l|}{ Location of start-up in Nairobi ${ }^{2}$} \\
\hline Ngong Road & 3 & $12 \%$ \\
\hline Kilimani & 4 & $16 \%$ \\
\hline Westlands & 4 & $16 \%$ \\
\hline Juja & 2 & $8 \%$ \\
\hline Thika Road (Kenyatta University) & 3 & $12 \%$ \\
\hline Madaraka Area (Strathmore University) & 6 & $24 \%$ \\
\hline No physical space (online-based) & 1 & $4 \%$ \\
\hline City Centre & 1 & $4 \%$ \\
\hline Upperhill & 1 & $4 \%$ \\
\hline \multicolumn{3}{|l|}{ Months/years since start-up's establishment } \\
\hline$<6$ months & 1 & $4 \%$ \\
\hline 6 months -1 year & 3 & $12 \%$ \\
\hline 18 months -2 years & 3 & $12 \%$ \\
\hline 24 months -3 years & 4 & $16 \%$ \\
\hline
\end{tabular}

2 Respondent 9's start-up has offices in both Nairobi and Eldoret. 


\begin{tabular}{|c|c|c|}
\hline 36 months-4 years & 6 & $24 \%$ \\
\hline 48 months-5 years & 4 & $16 \%$ \\
\hline 60 months-6 years & 1 & $4 \%$ \\
\hline 72 months-7 years & 3 & $12 \%$ \\
\hline \multicolumn{2}{|c|}{} & \\
\hline $\begin{array}{c}\text { Company hub that start-up was based at or } \\
\text { involved with at time of research }\end{array}$ & & \\
\hline Metta & 1 & $4 \%$ \\
\hline iHub & 5 & $20 \%$ \\
\hline iBiz Africa & 6 & $24 \%$ \\
\hline Chandaria BIIC & 3 & $12 \%$ \\
\hline KeMU Hub & 1 & $4 \%$ \\
\hline C4D Lab & 2 & $8 \%$ \\
\hline m:Lab East Africa & 1 & $4 \%$ \\
\hline Nairobi Garage & 1 & $4 \%$ \\
\hline SPRING accelerator & 1 & $4 \%$ \\
\hline Nailab & 3 & $8 \%$ \\
\hline \multicolumn{2}{|l|}{} \\
\hline Independent start-up (not involved with any \\
company hub)
\end{tabular}

\section{Findings and analysis}

We now present findings, drawn from the questionnaire responses, in terms of five themes:

- participation in tech hubs;

- internal collaboration;

- external collaboration;

- knowledge governance; and

- scaling.

\section{Participation in tech hubs}

Of the 25 start-ups surveyed, 10 were, at the time of the research, co-located with other start-ups in company hubs (according to the De Beer et al. (2017) company hub definition provided above); 14 had their offices in close proximity to other start-ups in a cluster hub (according to the De Beer et al. (2017) framing); and one was not interacting significantly with any hub. 


\section{In company bubs}

For the 10 start-ups in company hubs, the hubs were said to provide benefit through numerous opportunities for networking and developing business ideas, in addition to affordable and serviced offices. The resident start-ups rely on the open and interactive spaces within the hubs in order to meet new tech entrepreneurs and investors, access mentorship opportunities, remain aware of tech trends, and explore business and networking opportunities with other start-ups. According to respondent 5, whose start-up was working out of the iBiz Africa company hub:

iBiz Africa offers a platform where start-ups can share information, and the fact that [our] developers get to grow by sharing their challenges and technical problems with other developers at iBiz [is an added advantage]. This process [of interacting with other developers] helps our developers solve problems much faster.

A similar sentiment was provided by respondent 20, whose start-up has had substantial interactions with various tech hubs:

Involvement in accelerators and tech hubs has been a huge factor in our success. We met our first angel and institutional investors at [an] accelerator, and have expanded the business through networks built at various accelerators and tech hubs.

According to respondent 6 , the networking opportunities offered by company hubs are so crucial to business development that some start-ups seek to switch hubs once opportunities at one hub have been exhausted:

We have been at iBiz for the past two years, and feel that we have exploited all the networking opportunities, including getting business from other start-ups working at $\mathrm{iBiz}$, and have saturated that window of opportunity. Moving to a workspace with a similar set-up, such as Nairobi Garage, would afford us more networking opportunities and a chance to interact with other start-ups at the hub, including competitors that are in the same space, so as to understand the dynamics at play.

\section{In cluster hubs}

Among the 14 start-ups with offices in geographical clusters of start-ups, the two located in Westlands, a Nairobi suburb, cited the advantages of the area's many IT companies and IT start-ups, hence allowing easy interaction and exploration of ideas. 
Also extolling the virtues of participation in a cluster hub was respondent 4, from a start-up located in the Ngong Road cluster hub:

The area around Ngong Road and Kilimani is a cluster for tech hubs and tech start-ups. [...] [We] had offices along Kilimani Road, Adams Arcade, and then moved to our current location on Ngong Road. [We] moved office as [we] scaled [...]. The clustering of tech companies [increases] the ease of sharing experiences, networking, learning from shared experiences, and growing as a start-up/company.

\section{Internal collaboration}

\section{Use of open-plan offices}

All the interviewees extolled the virtues, for all or most of their internal activities, of open-plan office set-ups in which teams-in particular, developer teams-are able to work openly and collaboratively. In the words of respondent 20: "[we] have an open work [space where] all teams are mixed and work collaboratively". According to respondent 8, from a start-up based at the iBiz Africa company hub, an open-plan office "provides the opportunity to network and collaborate with other start-ups that operate from iBiz". Two of the start-ups had opted for closed offices for their senior management combined with open-plan areas for their tech developers, allowing developers to easily share ideas and collaboratively solve technical problems. Respondent 18's start-up had its offices in a townhouse where its founders lived and which had an open-plan office set-up. Respondent 21's start-up had previously been hosted in an incubator hub with shared offices. As the start-up grew in size, it needed more space, and it opted to move to a private space where, among other things, it was better able to establish its own company culture. In the new space, it had adopted "[an] open office setup, [but also] with separate quiet/thinking rooms" (respondent 21).

\section{Use of online platforms}

The start-ups carrying out substantial amounts of fieldwork also make extensive use of virtual open working environments. They tend to have physical meetings as a team only when absolutely necessary. Mostly they communicate and collaborate via online tools such as Slack, Scrum Agile, Jira, Trello, Basecamp, WhatsApp, and email. These tools have the necessary flexibilities, allowing for a mixture of in-office and remote collaborative working between the start-ups' founders, staff members (both parttime and full time), interns, and collaborators hired for specific tasks.

\section{Collaborative development of human capital}

On-the-job training, sometimes supplemented by the use of free online training resources, is the start-ups' preferred mode of human resource development. In addition to being a cost-effective form of human capital development for start-ups operating 
under tight financial constraints while seeking to grow and scale, on-the-job training was said to have numerous additional benefits. In the words of respondent 13:

[We] prefer on-the-job training and collaboration through learning. It offers a fulfilling experience for us. It also serves as an important avenue to spread the company culture while offering our interns a chance to grow from the ground up.

At respondent 23's start-up, one of the founders has developed a practical-oriented internal training programme targeted towards the specific needs of the start-up's trainees. Respondent 14's start-up uses YouTube Tutorials for any "heavy training" that members need. Respondent 18's start-up also uses YouTube as an online training resource, as well as free online courses offered on massive open online course (MOOC) platforms such as Coursera and edX. Training can also play an important role in product development at the start-ups - serving, in the words of respondent 13 , "as an avenue to innovate around existing products while coming up with new ideas and processes". According to respondent 15,

[...] training programmes [...] make the members of the start-up more resourceful, as well as better equipped to handle specific tasks that in turn would enable the members of the start-up to access their skills and knowledge in providing innovative client-based solutions. The training has also proved to be very useful to the members of the start-up in the competitive tech industry.

According to respondent 17, the knowledge acquired by Kenyan university students during their degrees is "[...] very theoretical and not practical enough". In the words of respondent 24, "[f] ormal education does not prove useful when running a startup". According to respondent 7:

The training offered [at respondent 7's start-up] is more hands-on, i.e., more practical. Despite the interns/students being in their final year of study [at university], they lack the hands-on skills required in the marketplace, which is very worrying. The students possess a lot of theoretical knowledge as opposed to practical skills.

Training can also have a strong personal empowerment dimension for employees. In the words of respondent 21, "training not only helps them get better at their individual roles, but also empowers their decision-making capabilities in their own personal lives". 


\section{Collaborative development of business ideas}

The respondents generally saw their start-ups' business idea-generation processes as being collaborative, and typically following one of three approaches: a spontaneous approach, a human-centred design approach, or a "lean canvas" approach (Maurya, 2012). Six respondents indicated that their start-ups are, to a great extent, spontaneous, i.e., do not adopt any specific formal process, in their origination of business ideas. In the words of respondent 12: "[when] any idea comes up, we SWOT it [conduct a strengths, weaknesses, opportunities and threats analysis], do market research, [then] work on it". According to respondent 2:

When an idea is pitched, a few of the team members will see if the idea is viable, and when the idea is deemed viable, they will map out the implementation of the idea into different phases. There is a communal system of sharing business ideas.

Ten respondents saw their start-ups' processes for developing business ideas as being primarily based on the observation of the needs and problems faced by potential customers, i.e., a human-centred design process. In the words of respondent 20 , from a start-up targeting the agricultural sector: "[t]ypically, business ideas are ideated to solve a problem; either one we are facing or one our customers are facing. We ideate collaboratively, implement, test and refine the solution." According to respondent 18: "We do customer research by building simple websites, marketing them and seeing how much interest they pull from potential customers." Respondent 4 explained the process in this way:

Ideas $[\ldots]$ come from customers and the solutions created are bespoke solutions to cater for the clients' needs. The process to create these bespoke solutions involves requirement-gathering, analysis of the client's legacy system, and the development of a proposed solution to solve the customer's pain point.

Four of the surveyed start-ups use elements often associated with the lean canvas technique to develop business ideas. The lean canvas technique involves team members collectively brainstorming ideas, capturing the ideas on a one-page canvas or flipchart, and then writing down a model for the implementation of the ideas (Maurya, 2012). In the words of respondent 21 , whose start-up was in the real estate sector: "[w]e use the lean canvas to brainstorm, and the validation board to experiment/go to market". According to respondent 2, whose start-up is in the bitcoin and fintech sector:

[w] hen an idea is pitched, a few of the team members at [the start-up] will see if the idea is viable, and when the idea is deemed to be viable, they will map out the implementation of the idea into different phases. There is a communal system of sharing business ideas. 


\section{External collaboration}

All the surveyed start-ups collaborate externally with other (non-rival) start-ups and individuals through various means, including joint ventures, strategic partnerships, consultancies, and contractual arrangements. For respondent 20's start-up, external collaborations are with a mix of both long-term partners and partners with whom the start-up engages on an as-needed basis:

We have an extensive partnership ecosystem of organisations including data suppliers, farmer organisations, development organisations, and financial institutions. We also engage with external consultants on an ad hoc basis.

According to respondent 20, "[c]ollaboration allows us to remain a lean team, while accessing the resources and expertise we need to succeed". In the words of respondent 21 in the online questionnaire: "[we] get resources we wouldn't be able to afford [if it] weren't ... for collaboration". And in the words of respondent 16: "[c]ollaboration reduces risks, shares resources, [and] improves expertise".

Respondent 14's start-up has found that external collaboration enables it to learn new things from its partners, especially in respect of the innovation process. According to respondent 17 , external collaborations benefit the start-up "through sharing of different ideas [and] approaches to growth". In the words of respondent 19, the main benefit of collaboration is that "[ $t]$ here are partners who come to complement our weakness with their strengths". Respondent 22 spoke of using collaborations with external partners to create new revenue streams and product lines. Respondent 15's start-up collaborates with public relations companies that can boost the start-up's public image and engage in community service work that the start-up would not be able to successfully perform.

For respondent 13's start-up, external partners provide access to additional African markets beyond Kenya:

The companies we have collaborated with have a wide reach across the African continent. They will play an important role in allowing us to scale faster, a process that would have taken a long while if we were to pursue these avenues ourselves.

At the same time, external collaborations are not without their challenges. While respondent 13's start-up has benefited from external collaborations, the respondent voiced a concern that, because the number of decision-makers increases, collaborations can slow down product development. Respondent 16 expressed the view that some collaborations can serve to limit a start-up's involvement with other potential partners. Respondent 23's start-up has experienced challenges in working with some 
non-governmental organisations (NGOs) and with Kenyan County governments, due to collaborations being halted as a result of lack of consistent funding or the termination of funding.

\title{
Knowledge governance
}

It was found that some of the start-ups have experienced what they regard as misappropriation of their ideas-by other start-ups, or individuals with whom they have collaborated. Respondent 20 gave the example of having discussions with potential start-up team members "who were thinking about similar products [and] who then went on to start a company with similar aspects to our work".

Among the 25 start-ups surveyed, only six were found to have used non-disclosure agreements (NDAs) to protect their knowledge, and a majority (13) had not yet engaged in any form of formalised knowledge protection or appropriation, such as via the intellectual property (IP) tools of trademarks, patents, utility models, or claims of copyright. Seven respondents said that their start-ups have copyright registrations (even though registration is not necessary in Kenya in order for copyright to exist in a work), two spoke of pending patents applications, five said that their start-ups have trademarks, and one spoke of the start-up having a trade secret. According to respondent 5, the value of IP to the start-up's business is to protect against copycats (both start-ups and established companies) using their ideas. In the words of respondent 4 :

\begin{abstract}
We put a lot of resources from the business's finances to develop products that are aimed for the mass market, so intellectual property protection provides a way for us to protect our long-term interests and avoid anyone else ripping-off our products for their own benefits. IP adds to the value of the whole company, like having patented solutions could increase the value of the company when it comes to valuation.
\end{abstract}

However, respondent 7's start-up has found the registration process for trademarks and patents with the Kenya Industrial Property Institute (KIPI) to be slow, and thus a poor use of time and resources. The start-up approached the IP office of a local university to assist with a patent application process, but found the university's process too involved. The general perception among most of the start-ups is that Kenya's patent and trademark registration processes are overly long, complicated, and expensive. Respondents 23 and 25 were of the view that their start-ups' resources are better spent on product development and on scaling the business than on the "secondary" priority of IP protection-although they acknowledged the importance of their start-ups finding ways to protect their IP.

Respondent 8 explained that in the fast-moving world of mobile app development, IP protections will not dissuade competitors from creating similar products and entering the market in which you trade: "So, we haven't really thought of patent- 
ing anything because, you know, information technology is based on growth: make something better and sell it." Respondents 3, 7 and 25 stated that for their start-ups, the first-mover advantage is more important for growth than patent protection. As respondent 25 explained: "As far as we know, there's no clear way to protect your knowledge or know-how. So how we [do it] is, we execute faster, before somebody else." Respondent 7 stated that in the world of technology, time is of the essence, so rather than "waste time" with patent protection, the aim of the respondent's startup was to "develop things and move first/fast into the market". Table 4 provides a picture of what the 25 respondents said were the modes of knowledge appropriation, and efforts at competitive advantage, used by their start-ups.

Table 4: Start-ups' modes of knowledge appropriation/protection and pursuit of competitive advantage

\begin{tabular}{|c|c|c|}
\hline $\begin{array}{c}\text { Modes of knowledge appropriation/protection used } \\
\text { by start-up }\end{array}$ & $\begin{array}{c}\text { No. of start- } \\
\text { ups }\end{array}$ & \% of start-ups \\
\hline None & 13 & $38 \%$ \\
\hline Copyrights & 7 & $21 \%$ \\
\hline Trademarks & 5 & $15 \%$ \\
\hline Trade secrets & 1 & $3 \%$ \\
\hline Patents (pending applications) & 2 & $6 \%$ \\
\hline Non-disclosure agreements (NDAs) & 6 & $18 \%$ \\
\hline & & \\
\hline Means used to compete with rival firms & & $32 \%$ \\
\hline Superior quality and affordability & 8 & $20 \%$ \\
\hline First-mover advantage & 5 & $16 \%$ \\
\hline Branding and marketing & 4 & $32 \%$ \\
\hline Product innovation & 8 & $0 \%$ \\
\hline Collaborations & 0 & \\
\hline
\end{tabular}

\section{Scaling ${ }^{3}$}

The start-ups were found to be seeking to scale through, among other things, enlarging their product ranges (e.g., by developing and commercialising new products), opening more outlets, entering new markets, and increasing their number of employees. For example, respondent 23's start-up at first offered its services for free, and later began charging a subscription fee. The start-up now launches new products for sale to its subscribers in order to increase the capacity of the company to scale.

3 For an in-depth treatment of approaches to innovation-scaling by start-ups and other knowledge-based enterprises in African settings, see Open AIR (2020), Scaling Innovation: How Open Collaborative Models Help Scale African Knowledge-Based Enterprises. 
Respondent 22's start-up found collaboration to be of great value in the pursuit of scaling, as it creates new revenue streams and product lines. And, as we saw above in section 6 on "external collaboration", respondent 13's start-up is seeking to scale "across the African continent" through external partnerships.

Respondent 9's start-up has changed its collaboration structure in order to pursue scaling. Initially the team at the start-up worked jointly and collaboratively on a single project. In order to scale, the team split into four teams of two each, to head four different projects simultaneously—including projects outside Nairobi, e.g., in the town of Eldoret, in western Kenya, where the start-up has established a second office.

Some start-ups have changed their business models in order to scale. At respondent 25 's start-up, the first business model, based on the start-up's development of a retail discount card platform, consisted of partnering with service providers to increase the service providers' sales. The next business model involved a shift to a mobile pointof-sale solution for the same service providers, which, according to respondent 25 , is more amenable to scaling. In the words of respondent 25 , “[...] we decided to pivot into a mobile point-of-sale [product], in the form of a mobile app that enables businesses to capture sales and purchases, record their expenses, and manage their stock".

\section{Conclusions}

The findings and analysis provided above suggest a number of cross-cutting drivers of the start-ups' collaborative innovation practices. Three key drivers are:

- openness;

- networking; and

- informality.

Openness is at the heart of Nairobi's mobile tech ecosystem, as exemplified by the start-ups' organisational set-ups, physical spaces, processes for developing business ideas, and modes of human capital development. Also, many of the approaches to knowledge governance adopted by the start-ups are grounded in an ethos of interaction and open collaboration, both internally and with external partners. We also consider the culture of openness by the start-ups as integral to their approaches to the scaling of their enterprises, as it allows them to optimise their business models while not losing sight of their specific product and service offerings. Further, openness facilitates networking and funding opportunities for the start-ups and enables additional skills development for team members. It is important to state that in respect to knowledge governance, some of the start-ups combine elements of both openness and protection, i.e., they consider certain aspects of their business knowledge to be open to all others, while other aspects are either kept confidential or closely guarded (with, in some cases, IP protections in place or being sought). 
The role of networking in the practices of start-ups is another prominent feature in the findings. Tech hubs are primary sources of networks for most of the start-ups, with the hubs connecting the start-ups with each other, with investors, and with other strategic partners. Collaborative external partnerships, forged through networking, are key drivers of the start-ups' innovation and enterprise development practices.

In respect of the third cross-cutting factor, informality, the mobile technology space in Kenya has, since the advent of M-PESA, witnessed an upsurge in mobile tech innovations driven largely by self-employed or freelance or part-time developers engaged in start-ups located within or around tech hubs. At the same time, it must be noted that some of these developers have engaged in the limited formalisation of certain aspects of their enterprises, e.g., through company registration, full-time employment for team members, written contracts with clients and consultants, NDAs for third parties, and use of the IP system. Thus, there is evidence of the start-ups bridging between, and harnessing, both informal and formal modalities within a general pursuit of open, networked collaboration. This bridging of informal and informal elements is also present in the start-ups' human capital development modalities, with almost all the start-ups in the study emphasising the need to supplement formal education for their team members with practical, and largely informal, onthe-job skills training.

\section{References}

Adesida, O., Karuri-Sebina, G., \& Resende-Santos, J. (Eds.). (2016). Innovation Africa: Emerging hubs of excellence. Emerald.

Adongo, L. E. (2015, September 20). Why fintech developers should pay attention to the opening of M-PESA's API [Blog post]. FSD Kenya. https://fsdkenya.org/blog/ why-fintech-developers-should-pay-attention-to-the-opening-of-m-pesas-api-2/

Bahrami, R. (2016, May 11). 4 powerful employee training tips for startups [Blog post]. Capterra. http://blog.capterra.com/4-powerful-employee-training-tips-for-startups/

Boateng, P. (2015, April 14). Africa needs IP protection to build knowledge economies. SciDevNet. $\quad$ https://www.scidev.net/global/intellectual-property/opinion/africa-needs-ip-protection-build-knowledge-economies.html

Bowmans. (2012). Kenya's Vision 2030: Creating more dinner space for SMEs on the IP table. https://www.bowmanslaw.com/insights/kenyas-vision-2030-creating-moredinner-space-for-smes-on-the-ip-table/

Bright, J. (2016, December 9). Africa's tech hubs. TechCrunch. https://techcrunch. com/2016/12/09/africas-tech-hubs

Bry, N. (2014). Frugal innovation in Africa: Low-tech for creative mobile services [Blog post]. Seedstars. https://www.seedstarsworld.com/blog/2014/12/frugal-innovation-africa-low-tech-creative-mobile-services/

Comins, N. R., \& Kraemer-Mbula, E. (2016). Innovation bubs in Southern Africa. In O. Adesida, G. Karuri-Sebina, \& J. Resende-Santos (Eds.), Innovation Africa: Emerging bubs of excellence (pp. 37-98). Emerald.

https://doi.org/10.1108/978-1-78560-311-220151003 
Communications Authority of Kenya (CAK). (2020). Third quarter sector statistics report for the financial year 2019/2020 (January—March 2020). https://ca.go.ke/document/ sector-statistics-report-q3-2019-2020/

De Beer, J. (2017). Open innovation in development: Integrating theory and practice across open science, open education and open data. Open AIR Working Paper 3. Open African Innovation Research (Open AIR) network. https://openair.africa/open-innovation-in-development-integrating-theory-and-practice-across-open-science-open-education-and-open-data/

De Beer, J., Armstrong, C., Oguamanam, C., \& Schonwetter, T. (Eds.). (2014). Innovation and intellectual property: Collaborative dynamics in Africa. UCT Press. http://openair. africa/innovation-and-intellectual- property-collaborative-dynamics-in-africa/

De Beer, J., \& Armstrong, C. (2015). Open innovation and knowledge appropriation in African micro and small enterprises (MSEs). The African Journal of Information and Communication (AJIC), 16, 60-71. https://doi.org/10.23962/10539/19315

De Beer,J., Millar, P., Mwangi, J., Nzomo, V., \& Rutenberg, I. (2017). A framework for assessing technology hubs in Africa. N.Y.U. Journal of Intellectual Property and Entertainment Law, 6(2),237-277.https://www.researchgate.net/publication/318710029_A_ Framework for Assessing Technology Hubs in Africa

Disrupt Africa. (2019). Funding report. https://disrupt-africa.com/funding-report/

Faems, D., Van Looy, B., \& Debackere, K. (2005). Interorganizational collaboration and innovation: Toward a portfolio approach. The Journal of Product Innovation Management, 22(3), 238-250. https://doi.org/10.1111/j.0737-6782.2005.00120.x

Finberg, R. (2015, September 6). M-Pesa opens up to 3rd party developers in Kenya as Safaricom launches API. Finance Magnates. https:/www.financemagnates.com/fintech/payments/m-pesa-opens-up-tp-3rd-party-developers-in-kenya-as-safaricomlaunches-api/

Firestone, R., \& Kelly, T. (2016, August 24). The importance of mapping tech hubs in Africa, and beyond [Blog post]. World Bank. https://blogs.worldbank.org/ic4d/importance-mapping-tech-hubs-africa-and-beyond

Gathege, D., \& Moraa, H. (2013). ICT hubs model: Understanding the key factors of the iHub model, Nairobi, Kenya. https://pdfs.semanticscholar.org/84e4/003ae1324b9001c09b543628a0144b8c4aea.pdf

Gebeya. (n.d.). [Website]. https://gebeya.com

Giuliani, D., \& Ajadi, S. (2019, July 10). 618 active tech hubs: The backbone of Africa's tech ecosystem. GSMA Ecosystem Accelerator. https://www.gsma.com/mobilefordevelopment/blog/618-active-tech-hubs-the-backbone-of-africas-tech-ecosystem/

Government of Kenya (GoK). (2005). Sessional paper No 2 of 2005 on development of micro and small enterprises for wealth and employment creation for poverty reduction.

GoK. (2007). Kenya Vision 2030. https://www.vision2030.go.ke

GSM Association (GSMA). (2016, August 5). A few things we learnt about tech hubs in Africa and Asia. Ecosystem Accelerator. https://www.gsma.com/mobilefordevelopment/programme/ecosystem-accelerator/things-learned-tech-hubs-africa-asia

Hersman, E. (2013). The mobile continent. Stanford Social Innovation Review. https://ssir. org/articles/entry/the mobile continent\# 
Jackson, T. (2016, December 16). Kenya's iHub to launch investment fund for African startups. Disrupt Africa. https://disrupt-africa.com/2016/12/kenyas-ihub-to-launchinvestment-fund-for-african-startups/

Jiménez, A., \& Zheng, Y. (2018). Tech hubs, innovation and development. Information Technology for Development, 24(1), 95-118.

https://doi.org/10.1080/02681102.2017.1335282

Kaigwa, M. (2010, August 20). 20 Kenyan web and tech innovations worth watching. Memeburn. https://memeburn.com/2010/08/20-kenyan-start-ups-worth-watching/

Kalanje, C. M. (2015). Role of intellectual property in innovation and new product development. World Intellectual Property Organisation (WIPO). https://www.wipo.int/sme/en/ documents/ip_innovation_development_fulltext.html\#role

Karuga, J. (2013). M-Farm: Giving Kenyan farmers the right connections. Nerw Agriculturalist. https://www.new-ag.info/en/developments/devItem.php?a=2909

Kemibaro, M. (2015, December 27). Kenya's 10 biggest technology trends from 2015. Moses Kemibaro. https://www.moseskemibaro.com/2015/12/27/kenyas-10-biggest-technology-trends-from-2015/

Kieti, J. (2013, March 1). Working with intellectual property rights in East Africa [Blog post]. iHub. https://ihub.co.ke/blogs/12389/working-with-intellectual-property-rights-in-east-africa

Kohli, T. (2015, February 19). Why Kenya, home to Africa's 'Silicon Valley', is set to be the continent's ultimate tech hub. Mail E Guardian.

Kuo, L. (2016, January 12). Silicon Savannah: African startups are defying the global tech slowdown. Quartz Africa. https://qz.com/592119/african-startups-are-defying-the-global-tech-slowdown/

Lawrence-Brown, A., \& Nieminen, M. (2016, May 10). How Kenyans are embracing mobile technology to access healthcare. The Guardian. https://www.theguardian.com/ sustainable-business/2016/may/10/how-kenyans-are-embracing-mobile-technology-to-access-healthcare

Levine, S. S., \& Prietula, M. J. (2014). Open collaboration for innovation: Principles and performance. Organization Science, 25(5), 1414-1443. https://doi.org/10.1287/orsc.2013.0872

Lopez Hernandez, A. K., Fernandez-Mesa, A., \& Edwards-Schachter, M. (2018). Team collaboration capabilities as a factor in startup success. Journal of Technology Management and Innovation, 13(4), 13-22. https://doi.org/10.4067/S0718-27242018000400013

Masinde, J. (2016, November 2). It's about to get easier for African innovators to protect their inventions. Quartz Africa. https://qz.com/825393/microsoft-4afrika-is-supporting-african-ip-registration-and-innovators-across-africa/

Maurya, A. (2012). Running lean: Iterate from plan A to a plan that works. O'Reilly Media.

McCormick, C. (2015, December 4). What is the difference between a tech startup and a startup that has a web and mobile smartphone presence? Quora. https://www.quora. com/What-is-the-difference-between-a-tech-startup-and-a-startup-that-has-aweb-and-mobile-smartphone-presence 
Mengistu, A., \& Imende, S. (2013). Kenya's mobile tech revolution. Selamta. https://www. selamtamagazine.com/stories/kenyas-mobile-tech-revolution

Moime, D. (2016, April 25). Kenya, Africa's Silicon Valley, epicentre of innovation [Blog post]. VC4A. https://vc4a.com/blog/2016/04/25/kenya-africas-silicon-valley-epicentre-of-innovation/

Moraa, H., Murage, K., \& Omenya, R. (2012). Perceptions from tech startups in Kenyan ICT hubs. iHub Research. https://ihub.co.ke/ihubresearch/uploads/2012/november/1354025437_819_126.pdf

Moringa School. (n.d.). About us. https://moringaschool.com/about-us

Mutegi, L. (2015, September 18). Safaricom finally opens M-PESA APIs to developers. CIO East Africa. https://cio.co.ke/news/main-stories/safaricom-finally-opens-m-pe$\underline{\text { sa-api-to-developers }}$

Mwangi, J. (2017, April 17). Mobile innovation as the cornerstone of socio-economic development in Kenya [Blog post]. CIPIT. https://www.cipit.activedimension.co.ke/ mobile-innovation-as-the-cornerstone-of-socio-economic-development-in-kenya/

Nsehe, M. (2011, August 2). The best African mobile apps: iCow. Forbes. https://www. forbes.com/sites/mfonobongnsehe/2011/08/02/the-best-african-mobile-appsicow/\#70bd72f71934/

Nzomo, V., Mwangi, J., Matu-Mureithi, L., Muchiri, C. W., \& Rutenberg, I. (2020). Modes of innovation and enterprise development by Nairobi's mobile tech startups. Open AIR Working Paper 22. Open African Innovation Research (Open AIR) network.

Open African Innovation Research (Open AIR). (2013). Knowledge and innovation in Africa: Scenarios for the future. https://openair.africa/knowledge-and-innovation-in-africa-scenarios-for-the-future/

Open AIR. (2020). Scaling innovation: How open collaborative models help scale African knowledge-based enterprises. https://openair.africa/scaling-innovation-how-open-collaborative-models-help-scale-africas-knowledge-based-enterprises/

Organisation for Economic Co-operation and Development (OECD). (2016). No country for young firms? STI Policy Note. https://www.oecd.org/sti/ind/Policy-Note-NoCountry-For-Young-Firms.pdf

Pasquier, M. (2014). Entering Kenya's mobile market. Innovation is Everywhere. https:// www.innovationiseverywhere.com/mobile-market-kenya/

Pembroke, B. (2016, July 30). No one can do it alone: Open collaboration to power the next generation of African ventures. HuffPost. https://www.huffingtonpost.co.uk/ beatrice-pembroke/noone-can-do-it-alone-ope b 7906372.html

Pivoteast. (2013, March 1). John Kieti transitions from the m:Lab. https://pivoteast.com/ pivot/john-kieti-transitions-mlab/

Republic of Kenya. (2012). Micro and Small Enterprises Act, No. 55 of 2012. https://www.industrialization.go.ke/index.php/policies/99-micro-and-small-enterprises-act-2012

Robehmed, N. (2013, December 16). What is a startup? Forbes. https://www.forbes.com/ sites/natalierobehmed/2013/12/16/what-is-a-startup/\#3d176f424c63

Rodman,J.(2016,October 20).Collaborative workplaces: What startups can teach large companies [Blog post]. https://ww.insights.wired.com/m/blogpost?id=6544125\%3ABlogpost $\% 3 \mathrm{~A} 142650$ 
Rouse, M. (2014, June). Startup culture. TechTarget. https://searchcio.techtarget.com/definition/startup-culture

Rutenberg, I. (2013, October 29). Faking it: Time to rethink intellectual property in developing countries? The Guardian. https://www.theguardian.com/global-development-professionals-network/2013/oct/29/intellectual-property-rights-google

Safaricom. (n.d.). M-PESA API. https://www.safaricom.co.ke/business/corporate/m-pesapayment-services/m-pesa-api

Smith, M. L., \& Reilly, K. M. A. (Eds.). (2013). Open development: Networked innovations in international development. MIT Press and International Development Research Centre (IDRC). https://www.idrc.ca/en/book/open-development-networked-innovations-international-development

Smith, M. L., \& Seward, R. K. (Eds.). (2020). Making open development inclusive: Lessons from IDRC experience. MIT Press and International Development Research Centre (IDRC). https://idl-bnc-idrc.dspacedirect.org/bitstream/handle/10625/59418/ IDL-59418.pdf

Steiber, A., \& Sverker, A. (2020). Corporate-startup co-creation for increased innovation and societal change. Triple Helix, 7, 1-23. https://doi.org/10.1163/21971927-bja10004

The Economist. (2012, August 25). Upwardly mobile: Kenya's technology start-up scene is about to take off. https://www.economist.com/node/21560912/

User Testing. (2018, December 5). IDEO's human centered design process: How to make things people want [Blog post]. https://www.usertesting.com/blog/how-ideo-uses-customer-insights-to-design-innovative-products-users-love/

Viffa Consult. (2015, May 15). Intellectual property: A case review of Kenya's IT sector. https:/viffaconsult.co.ke/intellectual-property-a-case-review-of-kenyas-it-sector/

Wahu, A. (2017, February 9). What Moringa School taught me that campus did not [Blog post]. Moringa School. https://moringaschool.wordpress.com/2017/02/09/whatmoringa-school-taught-me-that-campus-did-not

Wanjohi, N. (2014, February 5). Finding the right intellectual property lawyer for your innovative venture. Afromum. https://www.afromum.com/finding-the-right-intellectual-property-lawyer-for-your-innovative-venture/

World Bank. (2016). Tech hubs and incubators in Africa. https://pubdocs.worldbank.org/ en/765531472059967675/AFC42460-081716.pdf

World Intellectual Property Organisation (WIPO). (2016). IP facts and figures 2016. https:// www.wipo.int/edocs/pubdocs/en/wipo pub 943 2016.pdf

\section{Appendix: Questionnaire}

1. Name of start-up?

2. Name of interviewee? Position at start-up?

3. Date of establishment of the start-up?

4. How long has your start-up been in operation?

5. Location of the start-up and why?

6. Has your start-up had offices in another location/other locations? If so, what were the reasons behind your start-up having offices at these other locations and what was the reason for your re-location to your current offices/office space?

7. How is your office space organised for teams at work? 
8. Type of registration of the start-up? (business, company, LLP etc.)

9. Details of founders of the start-up? (e.g., name, designation, level of education, expertise, age, gender)

10. Has the structure of your start-up changed since the company was founded? (e.g., change in management, have some of the founders left the company? etc.)

11. Total number of staff at the start-up?

12. What problem(s) does your "mobile tech" start-up aim to solve and how?

13. What is your start-up's leading product/service?

14. Do you consider yourself to be in the mobile tech space and why?

15. Has your start-up had any interaction/involvement with any tech hub(s), e.g., incubator, accelerator, co-working space? Why?

16. How has any interaction/involvement with any tech hub(s), e.g., incubator, accelerator, co-working space, affected your start-up? Why?

17. Typically, how are business ideas developed and tested at your start-up?

18. Typically, how are intangible business assets (know-how, ideas, and processes) protected at your start-up?

19. Typically, how is business knowledge shared at your start-up among the core staff members and other staff members/consultants that work in conjunction with your start-up?

20. Typically, how is customer business knowledge shared at your start-up?

21. Does your start-up have any contracts in place with its core team and other staff, etc.?

22. Does your start-up have any contracts in place with customers?

23. Does your start-up have any contracts in place with business partners?

24. How do you collaborate with other companies or external individuals in your operations?

25. Does your start-up have competitors? If so, how does it maintain a competitive edge?

26. Does your start-up have copycats? If so, explain with examples of how you deal with copycats.

27. How does your start-up generate revenue?

28. How does your start-up plan to scale up its business?

29. How does your start-up plan to make its business sustainable?

30. What types of funding has your start-up received? If so, what percentage of total expenditure is accounted for by external funding?

31. What means do you use to protect your innovation(s)?

32. Do you employ any intellectual property protection in your start-up? Why? Why not? Which types? How?

33. What is your perception of the value of intellectual property protection to your business?

34. Do you utilise third party software in your operations? If yes, which software and why?

35. What contribution, if any, does mobile tech innovation have to the society in Kenya?

36. What is missing/lacking in the mobile tech space to ensure growth? 